that our measurements were obtained under closed cell conditions in which there was no possibility of contamination by daylight entering at the blanket's edge. Our measurements also showed that of the $74 \%$ of light transmitted by our samples, approximately $46 \%$ was scattered light which, due to its angle of incidence with the infant's skin, would be less effective than that normally incident at 90 degrees. Our findings lead us to concur with Dr Stutchfield and colleagues that thermal blankets will significantly reduce the effective irradiance of a phototherapy source.

Commercial phototherapy units vary widely in their outputs in the $420-480 \mathrm{~nm}$ range, and these outputs are generally suboptimal. ${ }^{12}$ Many of these older phototherapy units are still in use. We suggest the use of more modern light sources, which do reliably achieve the recommended minimum irradiance of $1 \mathrm{~mW} / \mathrm{cm}^{2}$, together with the avoidance of bubble plastic and other heat shields, whenever bilirubin concentrations are approaching exchange transfusion levels in very low birthweight babies. Heat and evaporative losses can be reduced instead by humidification. $^{3}$

' Stutchfield PR, Modi N, Weindling AM. Phototherapy and the use of heat shields in very low birthweight infants. Arch Dis Child 1988;63:552-4.

2 Modi N, Keay AJ. Phototherapy for neonatal hyperbilirubinaemia: the importance of dose. Arch Dis Child 1983;58: 406-9.

${ }^{3}$ Harpin VA, Rutter N. Humidification of incubators. Arch Dis Child 1985;60:219-24.
}

S C BAyliss and M J Moseley Departments of Physics and Ophthalmology, University of Leicester

B Hobss and D A Curnock Department of Neonatal Medicine and Surgery, City Hospital, Nottingham

\section{Diarrhoea due to breast milk: case of fucose intolerance?}

Sir,

We read with interest the report by Barfoot et al. ${ }^{1}$ Firstly, we would question whether five watery stools a day in a normally growing breast fed baby is abnormal. If the pressure from the parents to do something was so great that a formula change was necessary, however, we accept that Pregestimil, and subsequently SMA, at least benefited the parents.

Secondly, the authors recommend that 'sugar chromatography should be carried out on the stools of all infants with unexplained diarrhoea before changes are made in the diet.' We suggest this is impracticable, for the following reasons. The stool obtained must be liquid, and must be frozen within 15 minutes of leaving the rectum; this presents difficulties within a routine clinical setting, such as a district general hospital in England. In addition, the test may not be available at all centres. If the suggestion were followed to the letter, even the best organised laboratory would be inundated with tests.

It is true that in the patient described, using only the result of a test for stool reducing substances (Clinitest tablets) could have resulted in the mistaken diagnosis of lactose intolerance. The appropriate lesson from this report is that the diagnosis of lactose intolerance in a breast fed baby should not be accepted without question. It is of physiological interest that loose stools in breast fed babies may be due to oligosaccharides and their breakdown products, but the stool consistency tends to improve with time, and should not in general be taken as an indication to stop breast feeding.

\section{Reference}

1 Barfoot RA, McEnery G, Ersser RS, Seakins JW. Diarrhoea due to breast milk: case of fucose intolerance? Arch Dis Child 1988;63:311.

$\mathrm{Q}$ W SPENDER
Division of Clinical Nutrition,
Hospital for Sick Children
Toronto,
Ontario,
Canada M5G $1 X 8$

\section{Diarrhoea due to breast milk: case of fucose intolerance}

Sir,

I was interested to read the case report from Barfoot et al on fucose as a possible cause of diarrhoea in a breast fed baby. The authors finish by saying 'This type of intolerance to human milk is rare, and we could find no previously published reports'. Just 10 years ago in the same journal Whyte et al published a short report on exactly the same finding. ${ }^{2}$ They went further than the current authors in identifying oligosaccharides including particularly fucosyl lactose in the stools of $85 \%$ of healthy breast fed infants.

Barfoot et al offer no supportive evidence for their contention that their finding represents intolerance. It is common for healthy breast fed babies to have loose stools, and five a day is not that rare. As this baby was said to be gaining weight satisfactorily it could be argued that they did this baby a disservice by changing her to artificial feeds. Perhaps if they had read Whyte's paper this baby's mother would have been allowed to continue breast feeding and the effort involved in publishing their report avoided.

\section{References}

' Barfoot RA, McEnery G, Ersser RS, Seakins JW. Diarrhoea due to breast milk: case of fucose intolerance? Arch Dis Child 1988;63:311.

2 Whyte RK, Homer R, Pennock CA. Faecal excretion of 
oligosaccharides and other carbohydrates in normal neonates. Arch Dis Child 1978;53:913-5.

\author{
H BAumer \\ Plymouth General Hospital, \\ Longfield House, \\ Longfield Place, \\ Plymouth PL4 7JH
}

Drs McEnery and Seakins comment:

Certainly, healthy breast fed babies may have frequent loose stools. While it is difficult to define pathological diarrhoea, this infant's diarrhoea was sufficient to get him admitted to hospital despite the adequate weight gain. Both the mother and experienced ward staff felt that the infant's diarrhoea was excessive, despite my attempts to reassure them. Reducing substances were identified in the stools repeatedly, at a concentration of $1 \%$. The diarrhoea immediately resolved on changing to a succession of two other milks (Pregestimil and SMA), and has never returned since. If the baby had continued to be breast fed we do not know whether he would have thrived adequately. His mother declined my suggestion to resume breast feeding. In these circumstances, I believe, it is reasonable to assume that the milk oligosaccharides were responsible for the troublesome diarrhoea (associated with perianal soreness) and that he benefited by the change of milk.

Our observations do not contradict those of Whyte et al but underline the importance of diet in the interpretation of analytical findings and of collecting samples before dietary or other therapeutic manipulations.

\section{'. . . officiously to keep alive'}

Sir,

It is good to read articles such as those by Dr Walker and Professor Campbell, which are trying to achieve an appropriate ethical stance in the intensive care of newborn infants. ${ }^{12}$ I would entirely agree with Dr Walker that the patient should be treated as a person, the burden being the treatment and not the child. It is poor clinical judgment to continue with onerous and unrewarding treatment. Yet we must also beware of the denial mechanism by which parents and professionals can collude both in giving up too soon or going on too long. A study of perinatal psychology needs to be brought into the ethical debate too.

I also wonder whether it is a correct deduction on Professor Campbell's part to suggest that the incidence of stillbirth associated with spina bifida dropped in the early 1960 s only because of the introduction of a more optimistic surgical approach. This could also have correlated with the advent of neonatal resuscitation. It is hard for us to realise now that intubation and ventilation of infants was, at that time, a new skill in the labour ward. We need not paint ourselves blacker than we were!

\section{References}

1 Walker CHM. '. . . officiously to keep alive'. Arch Dis Child 1988;63:560-4.

2 Campbell AGM. Commentary. Arch Dis Child 1988;63:565-6.

J GoODALL

City General Hospital,

Newcastle Road, Stoke on Trent ST4 6QG

\section{Withdrawal of iodinated disinfectants at delivery decreases the recall rate at neonatal screening for congenital hypothyroidism}

\section{Sir,}

We recently reported transiently raised serum concentrations of thyroid stimulating hormone during early postnatal life in infants born to mothers whose skin had been disinfected with povidone-iodine (PVP-I) at delivery for epidural anaesthesia or caesarean section. ${ }^{1}$ This transient impairment of the thyroid function was particularly severe in breast fed infants with a 25 fold increase in the recall rate at neonatal screening for congenital hypothyroidism, and was attributed to iodine overload due to the appreciably raised iodine content of breast milk in women treated with PVP-I. ${ }^{2}$

Therefore, PVP-I was replaced in obstetrics by a noniodinated skin disinfectant (chlorhexidine $0.5 \%$ in isopropanolol $70 \%(\mathrm{CHL}))$. We compared the frequency distributions of serum thyroid stimulating hormone concentrations at the time of screening in our whole population of healthy breast or bottle fed full term infants, before $(n=4745)$ and during six months after $(n=1178)$ replacement of PVP-I by CHL. We considered separately infants born to mothers without (group 1) or with (group 2) skin disinfection. The table shows that the replacement of PVP-I by CHL entirely abolishes the differences between groups 1 and 2 in: (a) the frequency distributions of neonatal thyroid stimulating hormone concentrations and (b) the recall rate at neonatal screening under suspicion of congenital hypothyroidism (serum thyroid stimulating hormone concentration $>50 \mathrm{mU} / \mathrm{l})$ after the type of feeding (levels of significance as compared with group 1: $p<0.01)$. Except for the type of skin disinfectant used in the mothers, the two newborn populations studied presented with identical epidemiological characteristics; consequently, our observations further support the view that iodine overload and transient subclinical hypothyroidism in breast fed infants resulted from the use of PVP-I in the mothers.

In conclusion, iodine overload is a significant and often unrecognised cause of very transient hyperthyrotropinaemia ('false positive') at screening. ${ }^{3}$ Therefore, PVP-I should be carefully avoided in the neonatal period whenever possible, especially in areas like Belgium where, because of a rather low iodine supply in the population, ${ }^{3}$ the newborns are particularly sensitive to the antithyroid effects of iodine excess. 